13. Vogt. - Weitere Ergebnisse der Spaltlampenmikroskopie des vorderen Bulbusab. schnittes. Arch. f. Ophthal., Vol. CVI, p, 63, 1921. Reports two cases iv observed with the corneal microscope. Describes endothelial changes as golden 0 yellow crystalline pigment granules. Suggests that the endothelial changes may $\mathrm{O}$ precede those in the epithelium. Describes droplike elevations of the endothelial surface in elderly persons sometimes combined with pigment deposits. $\mathrm{He}$ considers the prominences as being Henle warts of Descemet's membrane.

14. Moeschler.--Untersuchungen ueber Pigmentierung der Hornhautrueckflaeche. Zeitsch. f. Augenheilk, Vol. XLVIII, p. 195, 1922. 94 persons over 50 with 176 eyes showed eight eyes with " tropfige Endothelprominenzen."

15. Graves.-A Bilateral Chronic Affection of Endothelial Face of the Cornea. Brit. Jl. of Ophthal., Vol. VIII, p. 502, 1924. Describes the following types: I. Few N elevations of endothelium at the centre of the cornea. II. More numerous elevations still limited to the centre of the cornea. III. $a$. Uniform distribution of elevations over a large part of the cornea $b$. Rounded discrete elevations in the periphery of the cornea with more complicated changes in the central area. IV. Same as type III with the additional appearance of transitory vacuoles in the epithelium.

\title{
AN UNCOMMON LUXATION OF THE LENS
}

BY

$$
\text { J. S. Steijn, M.D., }
$$

CHIEF ASSISTANT, UNIVERSITY EYE CLINIC, GRONINGEN

(DIRECTOR, PROF. DR. G. F. ROCHAT).

OCULISTS are well aware of the fact that after a blunt injury to the eye the lens may be luxated : either disappearing in the vitreous or entering the anterior chamber, or even escaping altogether from the eye through a rupture in the sclera. But I have never heard of a lens being completely reversed as in the following case.

An old woman came to the clinic complaining of severe pain in and above the right eye. She informed me that thirteen years ago she had a severe blow on the eye with a broomstick, and that the $c$ eye was blind since then, but that it had never given her any discomfort until three days ago.

In the anterior chamber a yellowish lens-shaped mass could be seen, nearly filling the whole chamber.

Examined with the slit-lamp, its surface, lying against the posterior surface of the cornea, showed a peculiar woolly appearance, closely resembling a small powder puff. It was taken for an 
abnormal kind of cataracta polaris anterior, that had formed on the surface of the luxated lens.

The blind, glaucomatous eye was enucleated, and microscopic sections were made. We were surprised to find that this powderpuff-like surface was in reality the posterior face of the lens. Under the thin capsule was a layer of loose, flocculent lens substance, which caused the peculiar appearance. The anterior surface, bearing a large wrinkled capsular cataract, was turned towards the vitreous, and was firmly attached to the anterior parts of the iris, which had slipped behind the lens. (See figure.) It is difficult to explain the mechanism that caused this complete retroversion of the lens.

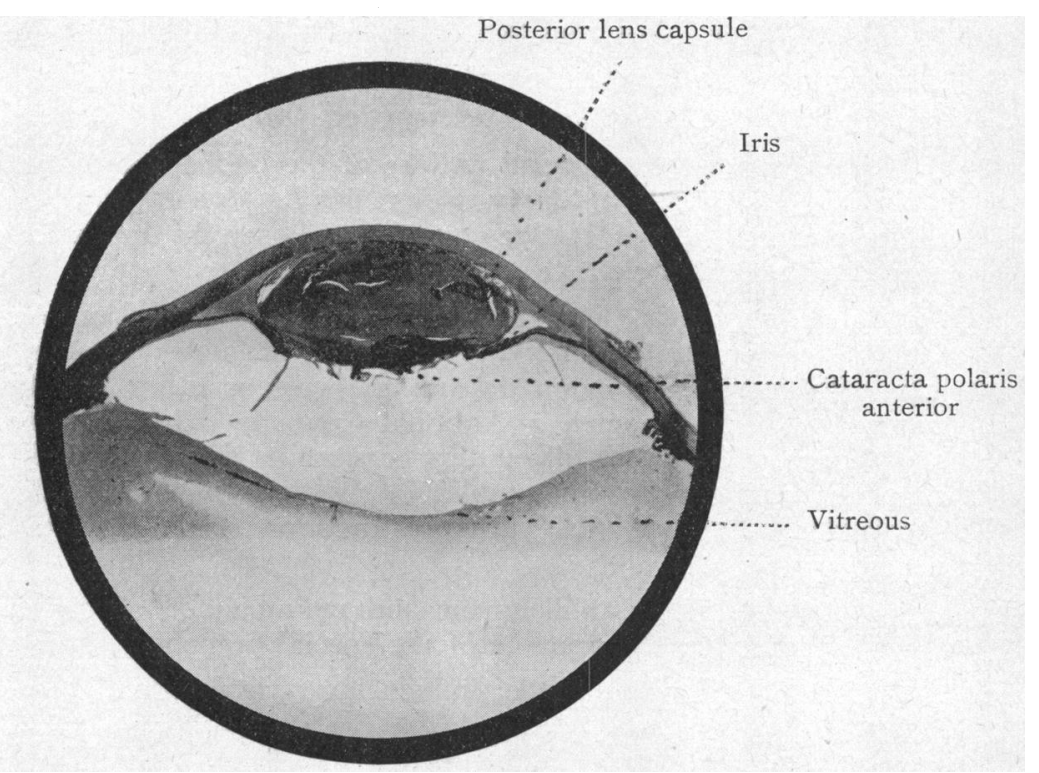

As, however, the patient's other eye was found highly myopic $(14 \mathrm{D})$, it is probable that the wounded eye was also myopic, and consequently had a liquefied vitreous, and a weakened zonula $Z$ innii. The blow with the broomstick may have ruptured the zonula and pushed the lens into the vitreous, which, in its liquefied condition, offered no resistance to the lens making half a revolution on its horizontal axis.

It is not uncommon for a luxated lens in the vitreous, entirely freed from its connections with the ciliary body, to slip back into the anterior chamber when the patient bends his head. This may have happened to our patient, and thus the lens may have re-entered the anterior chamber in the reversed position, in which it ultimately became fixed.

The posterior portion of the eyeball showed the ordinary signs of secondary glaucoma. 